\title{
SISTEM PENDUKUNG KEPUTUSAN PENANGANAN PASIEN UGD MENGGUNAKAN METODE FUZZY MULTIPLE ATTRIBUTE DECISION MAKING DENGAN SIMPLE ADDITIVE WEIGHTING PADA PUSKESMAS GAJAHAN SURAKARTA
}

\author{
Riza ${ }^{1)}$; Muhammad Hasbi ${ }^{2}$; Iwan Ady Prabowo ${ }^{3)}$ \\ 1) Program Studi Sistem Informasi, STMIK Sinar Nusantara \\ 2\} 3) Program Studi Teknik Informatika, STMIK Sinar Nusantara \\ 1) reizhaoconnor05@gmail.com; ${ }^{2)}$ mhasbi@sinus.ac.id; ${ }^{3)}$ iwanadyp@gmail.com
}

\begin{abstract}
In the Public Health Center, the handling of patients of the Emergency Unit is classified as not much happening because now many hospitals are ready to handle all forms of patient complaints. At the Public Health Center, the handling of patients in the Emergency Unit occurs only for mild illness and with outpatient treatment. To decide the condition of the patient should be treated in the room or should be referred to what hospital, the Center for Public Health has not been able to determine it so that for regular referrals addressed directly to a fully equipped hospital. The number of hospital types and the poor condition of the patient makes the decision making must be clear and appropriate to the actual patient condition. To overcome these problems, the authors make an application decision system with FMADM SAW method to determine where the patient should be handled further, surgery, ICU, road or hospitalization, a referral must be in accordance with the condition of the patient. The method used in the form of data analysis methods in the form of data collection techniques, data types, and system design. This application also has advantages in making report analysis results that can be done quickly and easily. To facilitate the implementation of the system, the authors limit the problem only on the problem of determining the purpose of treatment alone. The system that the author designed the decision-making system with FMADM SAW method. The result of analysis and design in the form of decision support system of patient handling of new Emergency Unit with computer-based and application of FMADM SAW method. The tested system will produce patient data information and result of decision support process of patient handling. From another process is given a form of separate data collection process according to the needs of the process of supporting patient handling decisions and considered feasible if the process is stored completely. It is hoped that this system can assist the Public Health Center admin in dealing with Emergency Room patients. Keywords: Decision Support System, Emergency Room, FMADM (SAW), Public Health Center
\end{abstract}

\section{PENDAHULUAN}

Unit Gawat Darurat (UGD) merupakan tempat pelayanan darurat untuk pasien yang butuh pertolongan medis segera yang di adakan di setiap Puskesmas atau Rumah Sakit. Perkembangan medis merupakan hal terpenting yang harus dijalankan agar pelayanan kepada pasien bisa tertangani dengan baik. Untuk menghindari adanya kematian pasien dikarenakan kondisi darurat, maka penanganan medis pertama adalah UGD, di setiap kondisi perkembangan pasien baik dan buruknya tidak boleh salah dalam penanganan.

Kriteria-kriteria yang telah ditentukan oleh pihak Puskesmas untuk bisa memutuskan suatu tindakan, akan lebih memperjelas kemana pasien akan dirawat. Karena banyaknya kriteria yang menjadi pertimbangan dalam memberikan pelayanan seorang Pasien jika terlalu parah dan peralatan puskesmas yang tidak memadahi maka bisa langsung dirujuk ke rumah sakit yang lebih baik.

Dari data yang ada dibutuhkan penanganan medis dan penunjang keputusan yang tepat, dengan sistem diharapkan dapat membantu penunjang keputusan penanganan pasien UGD.

Metode SAW ini dipilih sebagai pendamping FMADM karena metode ini menentukan nilai bobot untuk setiap atribut, kemudian dilanjutkan dengan proses penentuan bobot akhir yang akan menyeleksi alternatif dari sejumlah alternatif, dalam hal ini alternatif yang dimaksud adalah penanganan pasien UGD dengan kriteria-kriteria yang ditentukan. Dengan metode tersebut, diharapkan penanganan akan lebih tepat karena didasarkan pada nilai kriteria dan bobot yang sudah ditentukan sehingga akan 
mendapatkan hasil yang lebih akurat terhadap tujuan penanganan pasien lebih lanjut

\section{TINJAUAN PUSTAKA}

Puskesmas [1] adalah unit pelaksana teknis Dinas Kesehatan Kabupaten / Kota yang bertanggung jawab menyelenggarakan pembangunan kesehatan di suatu wilayah kerja. Pembangunan kesehatan yang dimaksud adalah penyelenggara upaya kesehatan untuk meningkatkan kesadaran, kemauan, dan kemampuan hidup sehat bagi penduduk agar dapat mewujudkan derajat kesehatan yang optimal. Pusat Kesehatan Masyarakat (Puskesmas) adalah organisasi fungsional yang menyelenggarakan upaya kesehatan yang bersifat menyeluruh, terpadu, merata, dapat diterima dan terjangkau oleh masyarakat [2].

Keperawatan

Gawat

Darurat

(Emergency Nursing) [3] merupakan pelayanan keperawatan yang komprehensif diberikan kepada pasien dengan injury akut atau sakit yang mengancam kehidupan. Sebagai seorang spesialis, perawat gawat darurat menghubungkan pengetahuan dan keterampilan untuk menangani respon pasien pada resusitasi, syok, trauma, ketidakstabilan multisistem, keracunan dan kegawatan yang mengancam jiwa lainnya.

Gawat darurat [4] adalah suatu keadaan yang mana penderita memerlukan pemeriksaan medis segera, apabila tidak dilakukan akan berakibat fatal bagi penderita. Instalasi Gawat Darurat (IGD) adalah salah satu unit di rumah sakit yang harus dapat memberikan pelayanan darurat kepada masyarakat yang menderita penyakit akut dan mengalami kecelakaan, sesuai dengan standar [5].

Sistem merupakan sekelompok elemen yang berinteraksi dengan maksud yang sama untuk mencapai suatu tujuan [6].

Sistem Pendukung Keputusan

[7] merupakan suatu sistem yang interaktif, yang membantu pengambil keputusan melalui penggunaan data dan model-model keputusan untuk memecahkan masalah yang sifatnya semi terstruktur maupun yang tidak terstruktur".

Fuzzy Multi-Attribute Decision Making (Fuzzy MADM) adalah salah satu metode yang bisa membantu pengambil keputusan dalam melakukan pengambilan keputusan terhadap beberapa alternatif keputusan yang harus diambil dengan beberapa kriteria yang akan menjadi bahan pertimbangan [7].

Metode SAW sering juga dikenal dengan istilah metode penjumlahan terbobot. Konsep dasar metode SAW adalah mencari penjumlahan terbobot dengan rating kinerja pada setiap alternatif pada semua atribut [8].

\section{METODE PENELITIAN}

\subsection{Analisis Sistem}

\subsubsection{Teknik Pengumpulan Data}

Teknik Pengumpulan data dalam penelitian ini menggunakan Studi Pustaka dan Observasi. Studi Pustaka dengan pengumpulan data dengan mempelajari paket modul dan panduan FMADM, buku-buku Penunjang SPK, buku-buku perpustakaan tentang Metode FMADM SAW. Observasi penulis mengamati langsung terhadap suatu kegiatan yang sedang berlangsung atau mengetahui proses-proses yang terjadi di UGD, tentang kondisi pasien, jenis pananganan dan pengambilan keputusan.

\subsubsection{Sumber Data}

Sumber data dalam penelitian ini terdiri dari data primer dan data sekunder. Data Primer berisi data pokok untuk proses analisa data berupa data Pasien, Data Pelayanan, data kriteria Penunjang Keputusan Penanganan Pasien.

Data Sekunder berisi data pembantu berupa model perancangan yang digunakan dalam analisa seperti Conteks, HIPO, ERD.

\subsection{Desain Sistem}

Penelitian atas sistem yang telah ada dengan tujuan untuk merancang system baru atau diperbarui.

\subsubsection{Diagram Kontek}

Data Flow Diagram Context Level (Konteks Diagram) berfungsi untuk memetakan model lingkaran tunggal yang mewakili keseluruhan sistem baik kesatuan luar berupa Dinas, Medis UGD, pasien.

\subsubsection{HIPO}

HIPO (Hierarchy Plus Input Process Output) alat desain dan tehnik dokumentasi dalam siklus perkembangan sistem dari top level sistem utama sampai level 1 percabangan dari input, proses dan output.

\subsubsection{Diagram Alir Data}

Diagram Arus Data (DAD) dijabarkan dengan mengacu pada Diagram Konteks dan HIPO, tetapi pada Diagram Arus Data ini lebih mengarah pada suatu proses dan merupakan gabungan proses secara keseluruhan yang melibatkan semua kesatuan luar secara 
lengkap dan proses input output serta database yang terlibat. alur data yang dibuat berupa : Data Pasien, Data RS Rujukan, Data Kamar, Data Rekam Medik, Data Pemeriksaan, Data Proses Penunjang Keputusan

\subsubsection{Desain Database}

Database dibentuk dari kumpulan tabel. di antaranya sebagai berikut : Tabel induk (Master File), tabel transaksi (Transaction File), tabel laporan (Report File).

\subsubsection{Desain Input Output}

Desain input dalam sistem baru ini antara lain : desain input data Pasien, desain input data kriteria, input kamar, input data rujukan, rekam medik, Penunjang Keputusan.

Output sistem penunjang keputusan penanganan pasien UGD yaitu berupa laporan-laporan seperti laporan data pasien, laporan data kriteria, laporan kamar, laporan data rujukan dan lain-lain.

\subsection{Konstruksi/Pengkodean}

Aplikasi yang penulis gunakan menggunakan Visual basic 6.0 dengan koneksi database SQL server 2000. Koneksi dengan ODBC SQL Server.

\subsection{Pengujian}

Pengujian perangkat lunak ini menggunakan metode pengujian blackbox. Dimana pengujian blackbox berfokus pada persyaratan fungsional perangkat lunak yang dibuat. Dan juga menggunakan pengujian validitas, disini akan diuji seberapa akurat sistem dapat melakukan pekerjaannya.

\subsection{Implementasi}

Implementasi perangkat lunak ini digunakan di komputer desktop/ dan Notebook.

\section{HASIL DAN PEMBAHASAN}

\subsection{Aturan Bisnis}

\subsubsection{Sistem yang berjalan}

Sistem Pelayanan UGD yang lama pada Puskesmas Gajahan hanya merupakan pelayanan untuk pertolongan pertama pada masyarakat hanya untuk kondisi pemeriksaan dengan tindakan medis ringan saja, dan banyak digunakan sebagai sarana untuk pelayanan berobat dengan kondisi penyakit ringan, belum ada pelayanan rawat inap.

Untuk Tindakan medis yang berat pihak puskesmas hanya membuatkan surat rujukan medis ke Rumah Sakit yang mempunyai Peralatan lebih Lengkap. Untuk Pelayanan Gawat Darurat dilakukan pada pukul 08.00 WIB sampai dengan pukul 19.30 WIB.
Sistem Pelayanan UGD pada Puskesmas Gajahan yang sedang berjalan merupakan pelayanan Darurat untuk masyarakat dalam kondisi pemeriksaan ringan dan sampai kondisi rawat inap dengan kondisi pelayanan sesuai fasilitas yang dimiliki Puskesmas saja, dan jika pelayanan dan Fasilitas. Sistem Pelayanan Gawat Darurat yang sedang berjalan dilakukan 24 jam.

\subsubsection{Analisis FMADM}

Pemerintah Kota Surakarta yaitu standarisasi ISO 9001 : 2008, dan kriteria adalah sebagai berikut

1. Rujukan Darurat

2. Rujukan Operasi

3. Rujukan Inap

4. Rawat Inap

5. Rawat Jalan

Kriteria nilai bobot :

1. Sangat Penting (SP) $=4$ / (Rujukan Darurat)

2. Penting $(P)=3 /$ ( Rujukan Biasa )

3. Cukup Penting $(\mathrm{CP})=2 /$ ( Rawat Inap / Rujukan )

4. Kurang Penting $(\mathrm{KP})=1 /$ ( Rawat Jalan / Rawat Inap )

Tabel-tabel dari kriteria dengan nilai bobotnya masing- masing dapat dilihat pada Tabel 1 , Tabel 2 dan Tabel 3 berikut.

Tabel 1. Darurat

\begin{tabular}{|l|c|}
\hline \multicolumn{1}{|c|}{ Darurat } & NILAI \\
\hline Penyakit Ringan & 1 \\
\hline Operasi Ringan & 2 \\
\hline Penyakit Berat & 3 \\
\hline Operasi Besar & 4 \\
\hline Kondisi Kritis & 5 \\
\hline
\end{tabular}

Tabel 2. Fasilitas

\begin{tabular}{|l|c|}
\hline \multicolumn{1}{|c|}{ Fasilitas Medik } & NILAI \\
\hline Siap dengan spesialisnya & 1 \\
\hline Siap tanpa spesialisnya & 3 \\
\hline Belum siap & 5 \\
\hline
\end{tabular}

Tabel 3. Tindakan

\begin{tabular}{|l|c|}
\hline \multicolumn{1}{|c|}{ Tindakan } & NILAI \\
\hline Normal & 1 \\
\hline Tindakan Ringan & 2 \\
\hline Tindakan Menegah & 3 \\
\hline Tindakan Berat & 4 \\
\hline Tindakan Khusus & 5 \\
\hline
\end{tabular}

Tabel 4. Keputusan Keluarga

\begin{tabular}{|l|c|}
\hline \multicolumn{1}{|c|}{ Tindakan } & NILAI \\
\hline Rujukan & 5 \\
\hline Rawat Inap & 3 \\
\hline Pulang & 1 \\
\hline
\end{tabular}


Tabel 5. Data Pasien

\begin{tabular}{|l|l|l|l|l|}
\hline \multirow{2}{*}{ NAMA } & \multicolumn{4}{|c|}{ Kondisi Puskesmas } \\
\cline { 2 - 5 } & Darurat & Fasilitas & Tindakan & $\begin{array}{l}\text { Keputu } \\
\text { san }\end{array}$ \\
\hline Amanto & Operasi & Ringan & Bisa Ditangani & Tindakan \\
Tanpa Spesialis & Khusus & Pulang \\
\hline Reskika & $\begin{array}{l}\text { Penyakit } \\
\text { Ringan }\end{array}$ & $\begin{array}{l}\text { Siap Dengan } \\
\text { Spesialis }\end{array}$ & $\begin{array}{l}\text { Tindakan } \\
\text { Menegah }\end{array}$ & $\begin{array}{l}\text { Mengi } \\
\text { nap }\end{array}$ \\
\hline
\end{tabular}

Dari tabel pemohon, maka dapat dibuat tabel rating kecocokan setiap alternatif pada setiap kriteria.

Tabel 6. Rating Kecocokan Setiap Alternatif Pada Setiap Kriteria

\begin{tabular}{|l|c|c|c|c|}
\hline \multirow{2}{*}{ ALTERNATIF } & \multicolumn{5}{|c|}{ KRITERIA } \\
\cline { 2 - 5 } & $\begin{array}{l}\text { Darurat } \\
\text { (MAX) }\end{array}$ & $\begin{array}{l}\text { Fasilitas } \\
\text { (MAX) }\end{array}$ & $\begin{array}{l}\text { Tindaka } \\
\text { n (MAX) }\end{array}$ & $\begin{array}{l}\text { Keputusa } \\
\text { n (MAX) }\end{array}$ \\
\hline Rujukan Darurat (A1) & 0 & 3 & 5 & 1 \\
\hline Rujukan Operasi (A2) & 2 & 3 & 5 & 1 \\
\hline Rujukan Inap (A3) & 0 & 3 & 3 & 1 \\
\hline Rawat Inap (A4) & 2 & 1 & 3 & 1 \\
\hline Rawat Jalan (A5) & 2 & 1 & 2 & 1 \\
\hline
\end{tabular}

\section{Langkah - Langkah Penyelesaian}

1. Vektor bobot: $W=[4,3,2,1]$

2. Matrik Keputusan $X$ berdasarkan kriteria kecocokan

$X=\left[\begin{array}{llll}0 & 3 & 5 & 1 \\ 2 & 3 & 5 & 1 \\ 0 & 3 & 3 & 1 \\ 2 & 1 & 3 & 1 \\ 2 & 1 & 2 & 1\end{array}\right]$

3. Normalisasi matriks $X$ menggunakan persamaan

Darurat menggunakan normalisasi persamaan: $R_{i j}=\frac{C_{i j}}{\operatorname{Max} C_{i j}}$

(Jika $C_{i j}$ merupakan angka 0 maka $\operatorname{Max} C_{i j}$ akan dianggap 0 juga)

Fasilitas persamaan:

$R_{i j}=\frac{\operatorname{Min} C_{i j}}{C_{i j}}$ normalisasi

(Jika $\operatorname{Min} C_{i j \tilde{j}}$ merupakan angka 0 maka $C_{i j}$ akan dianggap 0 juga)

Tindakan menggunakan normalisasi persamaan:

$$
R_{i j}=\frac{C_{i j}}{\operatorname{Max} C_{i j}}
$$

(Jika $C_{i j}$ merupakan angka 0 maka

\footnotetext{
$\operatorname{Max} C_{\mathrm{ij} j}$ akan dianggap 0 juga)
}

r11 di dapat dari didapat dari pembagian ( nilai c yaitu 2 dibagi dengan nilai maksimal yaitu 2 ) $2: 2=1$

$$
\begin{aligned}
& \text { Alternatif A1 } \\
& \text { Alternatif A4 } \\
& r 11=\frac{0}{\operatorname{Max}(0 ; 2 ; 0 ; 2 ; 2)}=0 \quad r 41=\frac{2}{\operatorname{Max}(0 ; 2 ; 0 ; 2 ; 2)}=1 \\
& r 12=\frac{3}{\operatorname{Max}(3 ; 3 ; 3 ; 1 ; 1)}=1 \quad r 42=\frac{1}{\operatorname{Max}(3 ; 3 ; 3 ; 1 ; 1)}=0,3 \\
& r 13=\frac{5}{\operatorname{Max}(5 ; 5 ; 3 ; 3 ; 2)}=1 \quad r 43=\frac{3}{\operatorname{Max}(5 ; 5 ; 3 ; 3 ; 2)}=0,6 \\
& r 14=\frac{1}{\operatorname{Max}(1 ; 1 ; 1 ; 1 ; 1)}=1 \quad r 44=\frac{1}{\operatorname{Max}(1 ; 1 ; 1 ; 1 ; 1)}=1 \\
& \text { Alternatif A2 Alternatif A5 } \\
& \mathrm{r} 21=\frac{2}{\operatorname{Max}(0 ; 2 ; 0 ; 2 ; 2)}=1 \quad \mathrm{r} 51=\frac{2}{\operatorname{Max}(0 ; 2 ; 0 ; 2 ; 2)}=1 \\
& \mathrm{r} 22=\frac{3}{\operatorname{Max}(3 ; 3 ; 3 ; 1 ; 1)}=1 \quad \mathrm{r} 52=\frac{1}{\operatorname{Max}(3 ; 3 ; 3 ; 1 ; 1)}=0,3 \\
& r 23=\frac{5}{\operatorname{Max}(5 ; 5 ; 3 ; 3 ; 2)}=1 \quad r 53=\frac{2}{\operatorname{Max}(5 ; 5 ; 3 ; 3 ; 2)}=0,4 \\
& \mathrm{r} 24=\frac{1}{\operatorname{Max}(1 ; 1 ; 1 ; 1 ; 1)}=1 \quad \mathrm{R} 54=\frac{1}{\operatorname{Max}(1 ; 1 ; 1 ; 1 ; 1)}=1 \\
& \text { Alternatif A3 } \\
& \begin{array}{l}
r 31=\frac{0}{\operatorname{Max}(0 ; 2 ; 0 ; 2 ; 2)}=0 \\
r 32=\frac{3}{\operatorname{Max}(3 ; 3 ; 3 ; 1 ; 1)}=1
\end{array} \\
& r 33=\frac{3}{\operatorname{Max}(5 ; 5 ; 3 ; 3 ; 2)}=0,6 \\
& r 34=\frac{1}{\operatorname{Max}(1 ; 1 ; 1 ; 1 ; 1)}=1
\end{aligned}
$$

Dari hasil perhitungan di atas maka didapat matriks ternomalisasi $\mathrm{R}$ sebagai berikut :

$\mathrm{R}=\left[\begin{array}{llll}0 & 1 & 1 & 1 \\ 1 & 1 & 1 & 1 \\ 1 & 0,3 & 0,4 & 1 \\ 0 & 1 & 0,6 & 1 \\ 1 & 0,3 & 0,4 & 1\end{array}\right]$

4. Mencari alternative terbaik menggunakan persamaan 2

Yaitu dengan mengkalikan nilai $\mathrm{R}$ dengan

Vektor bobot : $(W=[4,3,2,1])$

$\mathrm{V} 1=(0 \times 4)+(1 \times 3)+(1 \times 2)+(1 \times 1)=6$

$\mathrm{V} 2=(1 \times 4)+(1 \times 3)+(1 \times 2)+(1 \times 1)=10$

$\mathrm{V} 3=(1 \times 4)+(0,3 \times 3)+(0,4 \times 2)+(1 \times 1)=6,7$

$\mathrm{V} 4=(0 \times 4)+(1 \times 3)+(0,6 \times 2)+(1 \times 1)=5,2$

$\mathrm{V} 5=(1 \times 4)+(0,3 \times 3)+(0,4 \times 2)+(1 \times 1)=6,7$ 
Vektor V2 merupakan alternatif penanganan dengan nilai tertinggi karena memiliki nilai yang lebih besar dari nilai lain, V2 merupakan alternatif penanganan pertama dari kondisi alternatif, dan pasien dapat melakukan rujukan operasi dikarenakan kondisi mengharuskan pasien rujukan untuk operasi walaupun keinginan keluarga untuk pulang. Tapi dengan kondisi lain nilai tertinggi ke 2 adalah rujukan inap dan rawat jalan. Jadi pasien bisa rawat jalan dengan kondisi ditanggung keluarga.

Semakin besar nilai preferensi maka penanganan pasien sudah bisa diarahkan ke rujukan pasien.

Tabel 7. Contoh Penyelesaian Pasien UGD

\begin{tabular}{|c|c|c|c|c|c|c|}
\hline \multirow{2}{*}{ NAMA } & \multicolumn{5}{|c|}{ Kondisi Puskesmas } & \multirow{2}{*}{$\begin{array}{c}\text { Hasil } \\
\text { Alternatif } \\
\text { Penanganan }\end{array}$} \\
\hline & V1 & V2 & V3 & V4 & V5 & \\
\hline 1 & 2 & 3 & 4 & 5 & 6 & 7 \\
\hline Amanto & 6 & 10 & 6.7 & 5.2 & 6.7 & Rawat Jalan \\
\hline Reskika & 7.6 & 7 & 7.6 & 9 & 9 & Rawat Jalan \\
\hline Sujatmoko & 6 & 5.2 & 10 & 6.7 & 6 & Rujukan Inap \\
\hline Rima & 6 & 9 & 6.7 & 7.6 & 7 & $\begin{array}{l}\text { Rujukan } \\
\text { Operasi }\end{array}$ \\
\hline Candra & 6 & 5.2 & 6.7 & 10 & 6.7 & Rawat Jalan \\
\hline Sisilia & 6 & 10 & 7 & 9 & 6.7 & $\begin{array}{l}\text { Rujukan } \\
\text { Operasi }\end{array}$ \\
\hline Meisa & 9 & 7 & 7.6 & 7,6 & 9 & $\begin{array}{l}\text { Rujukan } \\
\text { Darurat }\end{array}$ \\
\hline Sutanto & 6 & 5.2 & 10 & 6.7 & 6 & Rujukan Inap \\
\hline Wisnu & 7.6 & 9 & 9 & 7 & 7.6 & $\begin{array}{l}\text { Rujukan } \\
\text { Operasi }\end{array}$ \\
\hline Meylia & 7.6 & 7 & 7.6 & 9 & 9 & Rawat Jalan \\
\hline Rahmat & 6 & 5.2 & 10 & 6.7 & 6 & Rujukan Inap \\
\hline Susanto & 6 & 9 & 6.7 & 7.6 & 7 & $\begin{array}{l}\text { Rujukan } \\
\text { Operasi }\end{array}$ \\
\hline Fatir & 7.6 & 7 & 7.6 & 9 & 9 & Rawat Jalan \\
\hline Heru & 7.6 & 9 & 9 & 7 & 7.6 & $\begin{array}{l}\text { Rujukan } \\
\text { Operasi }\end{array}$ \\
\hline Mela & 9 & 7 & 7.6 & 7,6 & 9 & $\begin{array}{c}\text { Rujukan } \\
\text { Darurat }\end{array}$ \\
\hline
\end{tabular}

Pada Tabel.7 menunjukkan bahwa Nilai Tertinggi merupakan alternatif pertama karena memiliki nilai yang lebih besar dari nilai lain, dan hasil penanganan alternatif pertama dari kondisi jika ada 2 alternatif pilihan dan keluarga pasien dapat melakukan tindakan keputusan dengan kondisi tanggung jawab di pihak keluarga pasien, dikarenakan kondisi puskesmas masih siap menangani pasien ataupun tidak pihak puskesmas hanya memberikan hasil tindakan yang harus dilakukan.

\subsection{Desain Sistem}

\subsubsection{Diagram Alir SAW Kriteria}

Diagram alir ini berfungsi untuk menggambarkan algoritma untuk proses FMADM SAW kriteria penanganan pasien. proses FMADM SAW kriteria ini dapat dilihat pada Gambar 1.

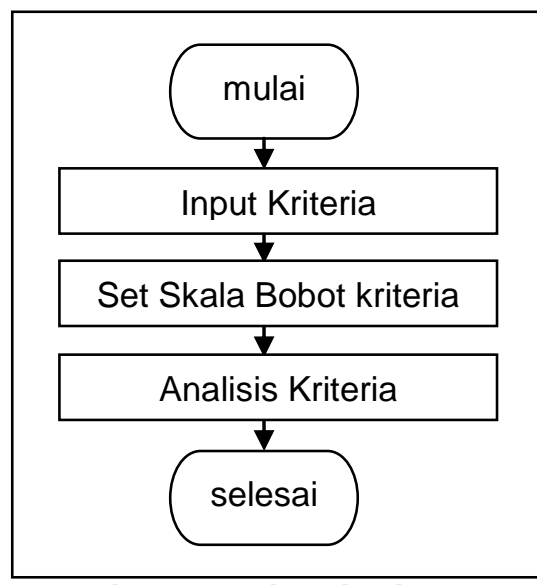

\section{Gambar 1. Diagram Alir Kriteria Penanganan Pasien}

\subsubsection{Diagram Konteks}

Diagram konteks menggambarkan arus data dari kesatuan luar (pasien, administrasi, dokter, dan pimpinan UGD) menuju sistem (sistem pendukung keputusan penanganan pasien) dan sebaliknya.

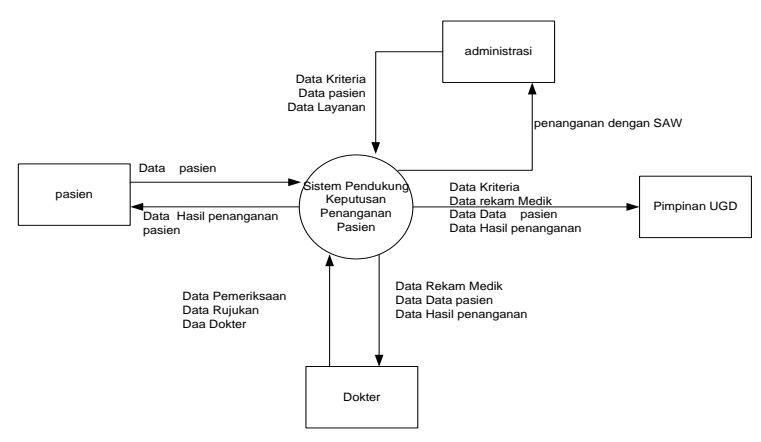

\section{Gambar 2. Diagram Konteks}

\subsubsection{HIPO}

Merupakan sistem paling awal dari Sistem penunjang keputusan penanganan pasien sebelum adanya turunan data dapat dilihat pada Gambar 3. 


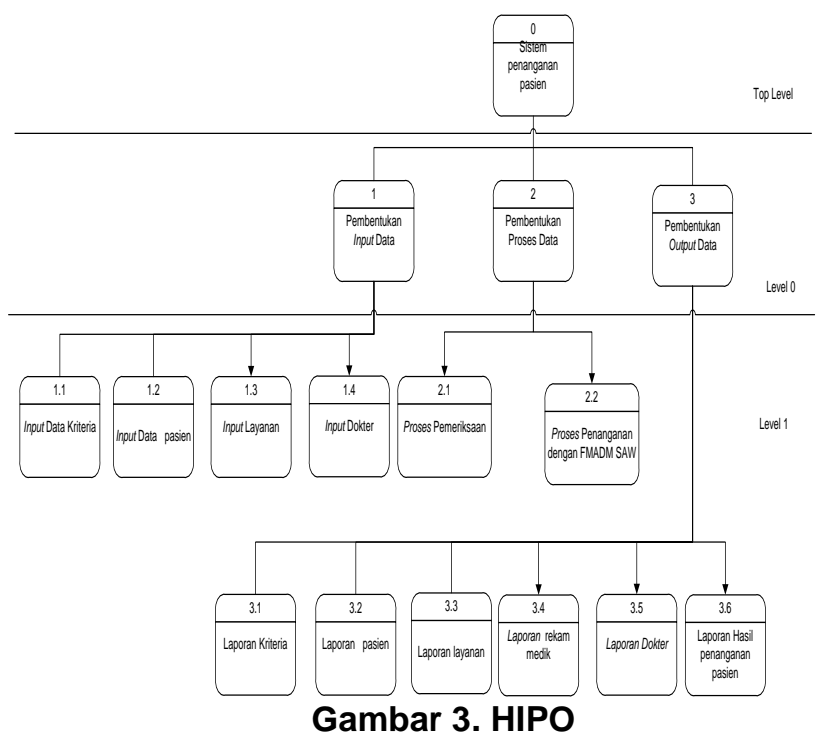

\subsubsection{Diagram Alir Data}

Diagram Alir Data merupakan diagram yang menggunakan simbol/kodetasi tertentu untuk menggambarkan alir dari suatu sistem informasi mulai input data, proses, dan output data dapat dilihat pada Gambar 4.

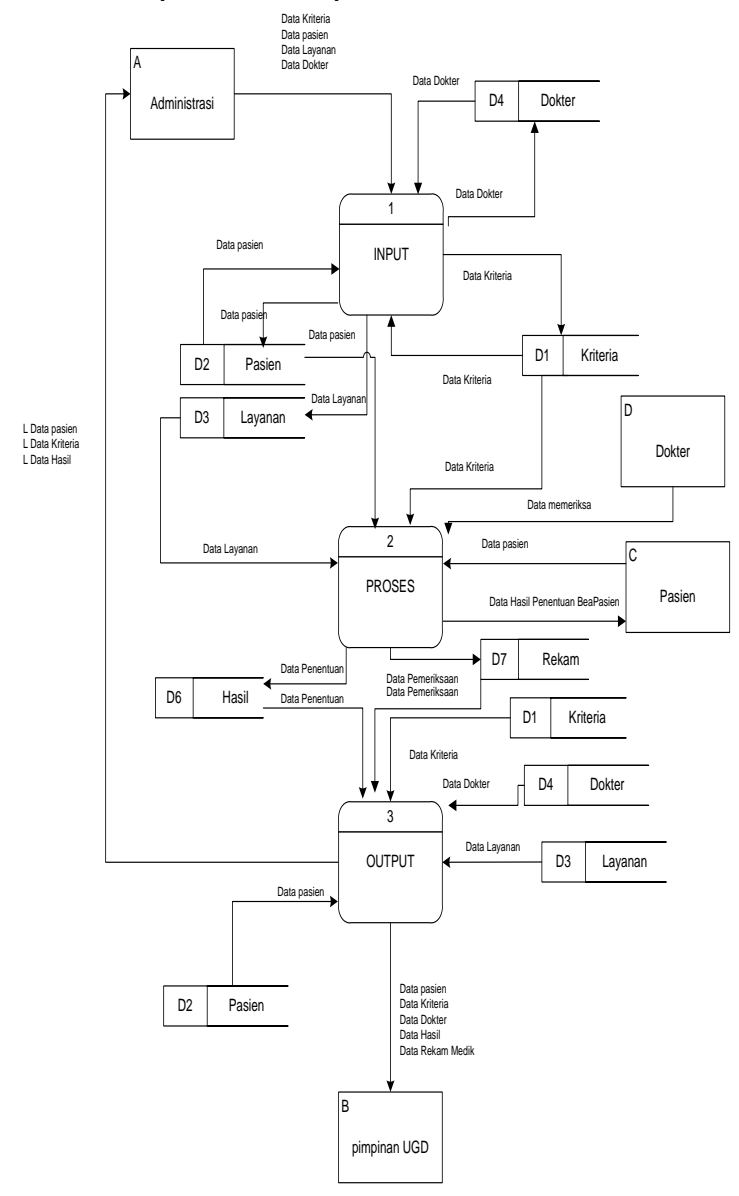

Gambar 4. DAD Level 0 Sistem Penunjang Keputusan Penanganan Pasien

\subsubsection{ERD}

Keterkaitan hubungan antara tabel tersebut dapat dilihat pada gambar 5 .

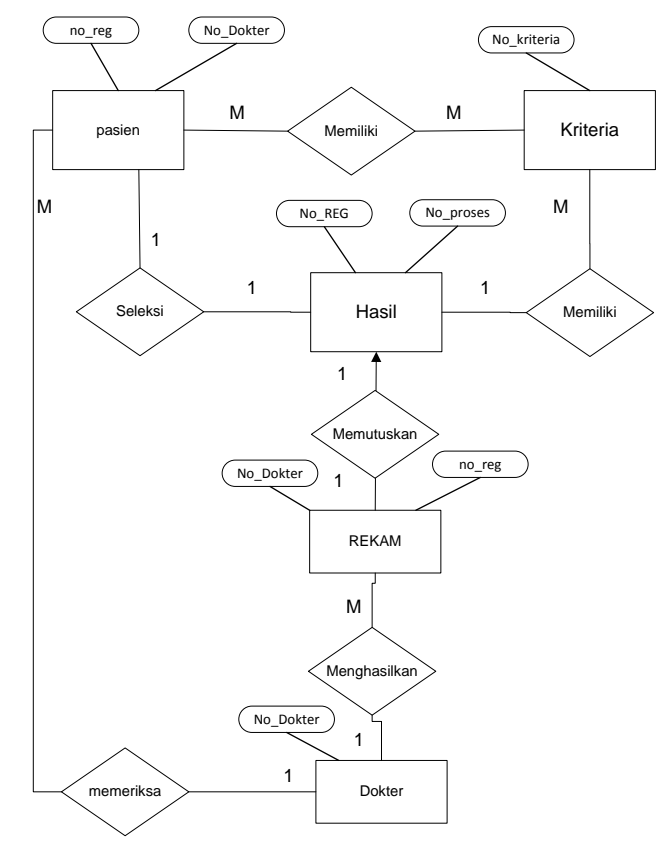

Gambar 5. ERD Hasil pasien

\subsection{Implementasi}

Sistem yang diusulkan berbentuk aplikasi yang menggunakan File Ext. Exe yaitu Penanganan_Pasien.exe. Dalam menu utama pengguna diberi hak untuk dapat mengganti tanggal sistem, dan jam sistem dengan cara klik Text tanggal atau Text jam seperti yang terlihat pada Gambar 6.

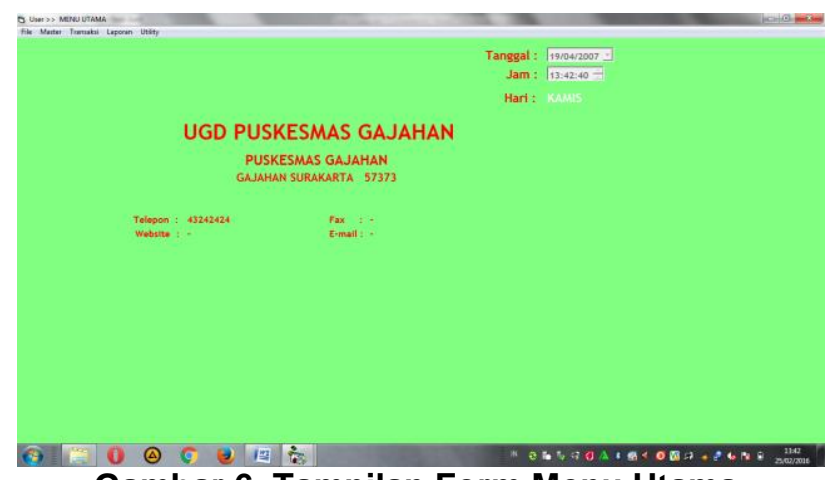

Gambar 6. Tampilan Form Menu Utama

Sistem juga dilengkapi dengan menu input data Kriteria, seperti terlihat pada Gambar 7. 


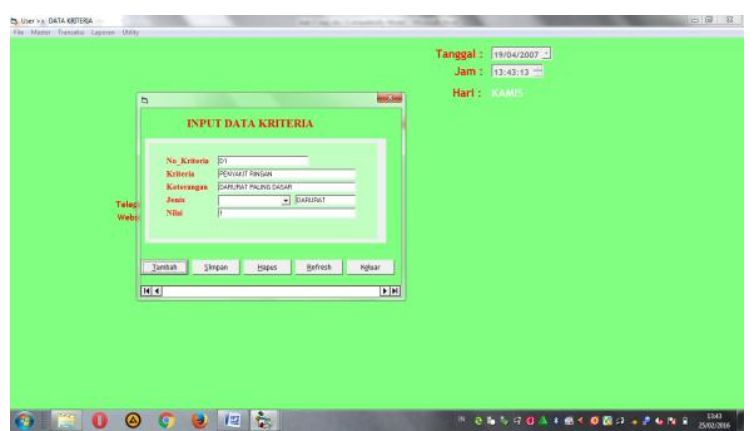

Gambar 7. Tampilan Data Kriteria

Pengelolaan data pasien diperlihatkan pada Gambar 8.

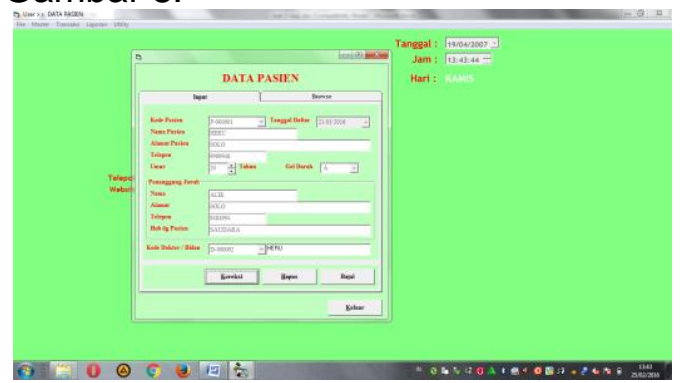

Gambar 8. Tampilan Data Pasien

Untuk menjalankan Proses Perhitungan klik menu Transaksi, klik input data perhitungan. Muncul isian data perhitungan (Gambar 9).

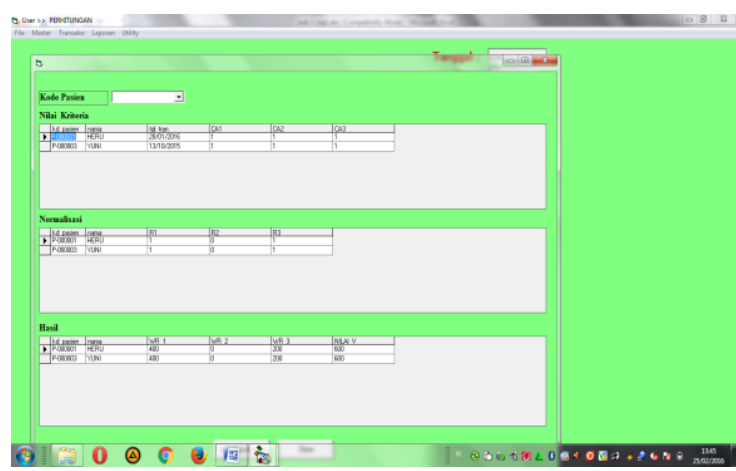

Gambar 9. Tampilan Data Perhitungan

Untuk keluar dari program aplikasi Pelayanan Pasien klik menu exit. Laporan data Hasil di gunakan untuk melaporkan data Hasil dengan menampilkan pilihan pencetakan ke layar atau ke printer sesuai kebutuhan seperti terlihat pada Gambar 10.

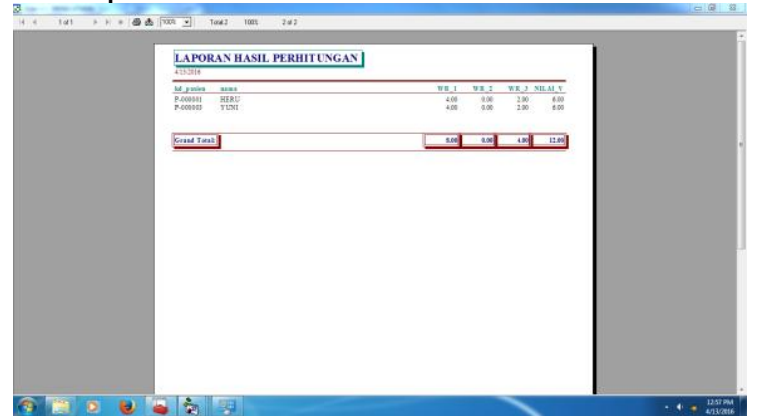

\subsection{Pengujian}

Pengujian fungsionalitas sistem menggunakan metode pengujian blackbox berdasarkan kasus pengujian pada aplikasi yang telah dibuat.

Tabel 8. Pengujian Fungsional Data Kriteria

\begin{tabular}{|c|l|l|l|l|}
\hline $\begin{array}{l}\text { Test } \\
\text { Case }\end{array}$ & Input Data & Target & $\begin{array}{l}\text { Output } \\
\text { Nyata }\end{array}$ & Sesuai \\
\hline 1 & Nomor: & Simpan Data & Data & Sesuai \\
& nama: & Data Sudah & Dikosongkan & \\
& Sukkriteria: & disimpan " & Simpan & \\
& Nilai: & Berhasil & \\
& Subkriteria2: & & & \\
& Nilai: & & & \\
& & & Data Tidak & Tidak \\
& & & Sessimpan & \\
\hline
\end{tabular}

Tabel 9. Pengujian Fungsional Data Pasien

\begin{tabular}{|c|c|c|c|c|}
\hline $\begin{array}{l}\text { Test } \\
\text { Case }\end{array}$ & Input Data & Target & Output Nyata & Sesuai \\
\hline 1 & $\begin{array}{l}\text { NIS: } \\
\text { Nama: } \\
\text { Alamat: } \\
\text { Umur: } \\
\text { Jenis } \\
\text { kelamin: }\end{array}$ & $\begin{array}{l}\text { Simpan } \\
\text { Data " Data } \\
\text { Sudah } \\
\text { disimpan " }\end{array}$ & $\begin{array}{l}\text { Data } \\
\text { Dikosongkan } \\
\text { Simpan } \\
\text { Berhasil } \\
\\
\text { Data Tidak } \\
\text { Tersimpan }\end{array}$ & $\begin{array}{l}\text { tidak } \\
\text { Sesuai }\end{array}$ \\
\hline
\end{tabular}

Tabel 10. Pengujian Fungsional Perhitungan

\begin{tabular}{|c|l|l|l|l|}
\hline $\begin{array}{l}\text { Test } \\
\text { Case }\end{array}$ & $\begin{array}{l}\text { Input } \\
\text { Data }\end{array}$ & Target & Output Nyata & Sesuai \\
\hline 1 & Pasien: & $\begin{array}{l}\text { Hasil } \\
\text { Proses } \\
\text { "Data } \\
\text { Berhasil " }\end{array}$ & $\begin{array}{l}\text { Data } \\
\text { Dikosongkan } \\
\text { Berhasil }\end{array}$ & Sesuai \\
& & & $\begin{array}{l}\text { Hasil Tidak } \\
\text { Keluar } \\
\text { Tidak } \\
\text { Tersimpan }\end{array}$ & tidak \\
& & & \\
\hline
\end{tabular}

Sistem yang diuji akan menghasilkan informasi data pasien, pasien, hasil proses penunjang keputusan penanganan. Dari proses yang lain diberikan satu form proses pendataan tersendiri sesuai kebutuhan proses penunjang keputusan penanganan pasien dan dianggap layak jika proses tersimpan dengan lengkap.

\section{PENUTUP}

\subsection{Kesimpulan}

Berdasarkan hasil penelitian dalam menganalisa dan mengimplentasikan sistem informasi Pelayanan UGD yang dilakukan oleh peneliti, maka dapat diambil beberapa kesimpulan, yaitu :

1. Input Data kriteria, input Data pasien, input Data pemeriksaan, Proses Perhitungan.

2. Laporan yang dihasilkan antara lain: Laporan Data kriteria ,Laporan pasien, 
Laporan pemeriksaan, Laporan hasil Pelayanan UGD.

3. Database yang digunakan antara lain : Tabel Data kriteria, Tabel Data pasien, Tabel Data pemeriksaan, table nilai_kriteria

\subsection{Saran}

Sistem informasi Pelayanan UGD ini diharap segera dapat digunakan sebagai pengolah data dan demi keamanan data maka setelah melakukan proses olah data perlu dilakukan pembackupan. Program aplikasi ini dibuat penulis supaya bisa digunakan sebagaimana mestinya.

\section{DAFTAR PUSTAKA}

[1] Sutrisno, Keperawatan Kegawat Daruratan, Jakarta: Media Aesculapins, 2013.

[2] A. Farich, Manajemen Pelayanan Kesehatan Masyarakat, Yogyakarta: Gosyen Publishing , 2012.

[3] J. A. Boswick, Perawatan Gawat Darurat, Jakarta: EGC, 2013.

[4] Hatmoko, Manajemen Kesehatan, Samarinda: Universitas Mulawarman, 2010.

[5] Pedoman Pelayanan Gawat Darurat, Jakarta: DepKes Ri, 1992.

[6] I. A. Prabowo, "Sistem Informasi Penerimaan Peserta Didik Baru SMA Negeri 1 Ngemplak Kabupaten Boyolali," Jurnal IImiah SINUS Vol 13, No 2, pp. 65-82, 2015.

[7] S. Kusumadewi, S. Hartati, A. Harjoko and R. , Fuzzy Multi-Attribute Decision Making (Fuzzy MADM), Yogyakarta: Graha IImu, 2006.

[8] N. Hermanto, "Sistem Pendukung Keputusan Menggunakan Metode Simple Additive Weighting (SAW) Untuk Menentukan Jurusan Pada SMK Bakti Purwokerto," Semantik 2012, pp. 52-62, 2012. 